\title{
Treatment of Basilar Artery Occlusion using Various Techniques of Interventional Radiology
}

\author{
Daniel Knap', Tomasz Kirmes ${ }^{2 *}$, Maciej Honkowicz², Marcin Koroński², Marzena Kysiak², Mateusz Bukański², Natalia Orlecka² and Jan
} Baron ${ }^{1}$

${ }^{1}$ Department of Radiology and Nuclear Medicine, Medical University of Silesia, Medykow Street 14, 40-752 Katowice, Poland

${ }^{2}$ Medical Scientific Society under the Department of Radiology and Nuclear Medicine, Medical University of Silesia, Medykow Street 14, 40-752 Katowice, Poland

\begin{abstract}
Basilar Artery Occlusion (BAO) is a rare cause of stroke, occurring in about $1 \%$ of all the cases. BAO is characterized by bad prognosis and high death rate, which is about $75-91 \%$. Neurological symptoms which accompany $\mathrm{BAO}$ are of large variety. BAO may occur suddenly, with or without previous prodromal symptoms or it may proceed progressively. Basilar artery occlusion always demands quick diagnosis and treatment. We are describing 5 cases of patients with basilar artery occlusion who were subjected to endovascular methods. The patients were treated with different intravascular techniques. Two patients had a stent Solitaire FR inserted, two others were applied targeted thrombolysis, one patient had combined therapy using targeted thrombolysis and mechanical thrombectomyPenumbra device. Neurological symptoms were determined by using National Institutes of Health Stroke Scale (NIHSS). $60 \%$ of patients achieved the result, according to NIHSS, equal 0 or 1 point or improvement of $\geq 10$ points, which is defined as neurological state changing for the better as well as the reduction of symptoms. Unblocking the basilar artery $(\mathrm{TICl} \geq 2 \mathrm{~b})$ was successful with $80 \%$ of patients. The lack of disability was stated with $40 \%$ of the group under treatment $(\mathrm{mRS} \leq 2)$. No patient had any complications connected with intravascular treatment. The treatment of basilar artery occlusion is difficult as nowadays there are no precise guidelines defining the most successful therapy. Our study shows that using intravascular methods is a good alternative for standard therapy of basilar artery occlusion, especially with those patients who cannot be qualified for intravenous thrombolysis due to overrunning the time window or with whom intravenous using of rt-PA was not efficient. The usage of endovascular methods is hoped to have great future prospects.
\end{abstract}

Keywords: Stroke; Basilar artery occlusion; Interventional radiology; Thrombectomy; Embolectomy

\section{Background}

\section{Anatomy}

Basilar artery comes into being as a combination of both vertebral arteries. In length it approximates the length of pons. It rarely follows the straight course but is mostly more or less curved. It runs along the basilar sulcus of pons and branches out into numerous ramifications which supply the brain with blood. These branches are: anterior inferior cerebellar artery, pontine arteries, labyrinthine artery, superior cerebellar artery and posterior cerebral artery. The branches of basilar artery supply occipital and temporal lobes of brain, pons, cerebellum, inner ear and others. In the interpeduncular fossa it separates into posterior cerebral arteries which are elements of the Willis' Circle.

\section{Epidemiology and risk factors}

Basilar artery is the artery most often affected with atherosclerosis of all the intracranial arteries [1]. Basilar artery occlusion may be also caused by: embolic material, dissection, aneurysm and inflammation [2]. In spite of many etiological factors of $\mathrm{BAO}$, this disease is a rare cause of stroke and occurs in about $1 \%$ of all cases [3]. BAO is characterized by bad prognosis and high death rate, which is about 75$91 \%[4,5]$. Risk factors of cerebral ischemic stroke (Table 1).

\section{Clinical symptoms}

Neurological symptoms accompanying BAO are characterized by great variety depending on the mechanism of obstruction development, its localization and collateral circulation [6]. The beginning of BAO may be sudden without prodromal symptoms, sudden with accompanying prodromal symptoms or it may proceed progressively with or without prodromal symptoms $[7,8]$. Basilar artery occlusion always demands quick diagnosis and treatment. The main symptoms of BAO (Table 2).

\section{Differential diagnosis}

Conditions to consider in the differential diagnosis of basilar artery occlusion were given in Table 3 .

\section{Treatment}

The main objective in treatment of the acute ischemic stroke is the restoration of cerebral blood flow. Instant recanalisation of blocked artery results in the improvement of patient's condition and is connected with the death rate reduction [9]. Ischemic stroke can be treated in two ways: pharmacologically, mainly by intravenous thrombolysis or with endovascular methods-mechanical thrombectomy (TM) and intra-arterial /targeted thrombolysis (TC). The standard method of curing ischemic stroke is intravenous fibrinolysis for which therapeutic window up to 4,5 hours. This method is characterized by low efficiency [10]. Using endovascular methods prolongs therapeutic window

*Corresponding author: Tomasz Kirmes, Department of Radiology and Nuclear Medicine, Medical University of Silesia, Medykow Street 14, 40-752 Katowice, Poland, Tel: 48-663-059-846; E-mail: tomaszkirmes@gmail.com

Received May 28, 2015; Accepted December 15, 2015; Published January 01, 2016

Citation: Knap D, Kirmes T, Honkowicz M, Koroński M, Kysiak M, et al. (2016) Treatment of Basilar Artery Occlusion using Various Techniques of Interventional Radiology. J Vasc Med Surg 4: 241. doi:10.4172/2329-6925.1000241

Copyright: $\odot 2016$ Knap D, et al. This is an open-access article distributed under the terms of the Creative Commons Attribution License, which permits unrestricted use, distribution, and reproduction in any medium, provided the original author and source are credited. 


\begin{tabular}{|l|}
\hline - Hypertension \\
\hline - Diabetes \\
\hline - Smoking \\
\hline - Hiperlipidemia \\
\hline - Atrial fibrillation \\
\hline - Oral contraceptives \\
\hline - Coronary artery disease \\
\hline - Obesity \\
\hline
\end{tabular}

Table 1: Risk factors.

- Decreased level of consciousness/coma

- Hemiparesis /quadriparesis, hemiplegia/quadriplegia

- Hypaesthesia or anaesthesia

- Cerebellar signs

- Vertigo, nausea, vomiting, directional nystagmus

- Disturbance of respiration, blood pressure and heart rate

- Headache,

- Incontinence

- Oculomotor signs

- Facial palsy

- Double vision, strabismus, skew deviation

- Tinnitus/hearing abnormalities

- Bulbar/pseudobulbar signs

- Hemianopia, blindness

Table 2: Symptoms and signs of basilar artery occlusion.

\begin{tabular}{|l|}
\hline - Subarachnoid haemorrhage \\
- Non-convulsive status epilepticus \\
- Hypoglycaemic or other metabolic coma, intoxication \\
- Hypoxic-ischaemic \\
- Bilateral hemispheric stroke \\
- Guillain-Barré syndrome or cranial neuritis, Miller-Fisher syndrome, botulism, \\
myasthenic crisis \\
- Basilar-type migraine \\
- Secondary brain tumours \\
- Primary brain tumours - specifically, cerebellopontine angle tumours \\
\hline - Lesions in the supratentorial hemispheric region, causing brainstem \\
compression and herniation \\
\hline - Basilar meningitis \\
\hline
\end{tabular}

Table 3: Differential diagnosis of basilar artery occlusion.

to 8 hours for targeted trombolysis and to 15 hours for mechanical thrombectomy $[11,12]$.

\section{Clinical Cases}

The study describes 5 cases of patients treated for basilar artery occlusion in 2010-2012. The group consisted of men aged 26-75 (mean age of 49). Neurological deficit was stated at time of admission and before the procedure according to modified National Institutes of Health Stroke Scale (NIHSS). In patients with suspected stroke CT was performed in order to exclude intracerebral hemorrhage, epidural and subdural hematoma as well as confirm and define the range of ischemia. CT angiography was used to identify and locate the occlusion. Two patients were performed MR-DWI. The main criteria qualifying for endovascular treatment were: clinical diagnosis of ischemic stroke, NIHSS $>4$ pts, strictly determined time of symptoms duration (for mechanical thrombectomy: up to 8 hours for anterior vascularity and up to 15 hours for posterior vascularity; for targeted trombolysis: up to 6 hours since the first symptoms occurred). The patients with BAO were treated with different intravascular techniques. Two patients had a stent Solitaire FR inserted, two others were applied targeted thrombolysis, one patient had combined therapy using targeted thrombolysis and mechanical thrombectomy-Penumbra device. After the procedure DSA was performed in order to estimate the vessel patency. TICI scale(Thrombolysis in cerebral infraction scale) was used for estimating the effectiveness of the procedure. The objective was to obtain the score $\geq 2 \mathrm{~b}$ according to TICI scale. After the procedure imaging CT/MRI (24-36 hours) was performed which aim was to reveal complications that could appear after intravascular treatment. The estimation of neurological symptoms was conducted in compliance with NIHSS: immediately after the intervention, in $24^{\text {th }}$ hour, in $7^{\text {th }}$ and $30^{\text {th }}$ days. The effect of treatment was considered positive if the result was equal 0 or 1 point in NHISS or improvement $\geq 10$ points. Modified Rankin scale (MRS) was used three months after the procedure to estimate the level of disability. MRS in $3^{\text {rd }}$ month $\leq 2$ was defined as a lack of disability.

\section{Intra-arterial thrombolysis}

Case 1: 49-year-old patient with suspicion of stroke. The patient was found on the day of admission with no verbal contact. According to his medical history the patient experienced an ischemic stroke in February 2010. In head CT lesions of vascular origins on various stages of evolution were diagnosed. The diagnosis was enlarged by performing head CT angiography which revealed ischemic stroke due to basilar artery and right posterior cerebral artery thrombosis. The patient was urgently qualified for intra-arterial thrombolysis during which $40 \mathrm{mg}$ of rt-PA was applied with no further complications. The intervention was performed by puncturing right femoral artery and inserting catheter to the right vertebral artery with Seldinger method. Then the diagnostic catheter was exchanged into the guiding catheter and a microcatheter was coaxially inserted into the basilar artery. $10 \mathrm{ml}$ of Actilyse was injected intra-arterial ly. Further on the microcatheter was inserted into P1 segment of the right posterior cerebral artery and another $20 \mathrm{ml}$ of Actylise was applied in two injections, receiving blood flow. The attempt to catheterize the right superior cerebellar artery was successful not before inserting $9 \mathrm{ml}$ of Actilyse into the point where it takes its origin. Then $1 \mathrm{ml}$ of Actylise was applied directly into the artery, receiving blood flow. In control test all branches of basilar artery were shown with right superior cerebellar artery slightly less filled. The patient's characteristics were shown in Table 4.

Case 2: 58-year-old patient with basilar artery occlusion in 15 $\mathrm{mm}$ long segment, recognized in CT angiography. The patient was disqualified from intravenous thrombolysis due to overrunning the therapeutic time window (time of symptoms duration-over 4,5 hours) and qualified for life-saving targeted thrombolysis. The intervention was performed by puncturing the right femoral artery and inserting catheter with Seldinger method and $40 \mathrm{mg}$ of rt-PA altogether was applied into the basilar artery, receiving blood flow. At the same time the narrowing in about half of the basilar artery's length, with no embolic materials, was revealed. In control DSA test all branches of basilar artery were shown. 12 hours later another control DSA test was performed, showing the appearance of occlusion in the distal segment of basilar artery. The control test of head CT showed ischemic stroke in brainstem, left occipital lobe, right temporal lobe and both cerebellar hemispheres. The patient's characteristics were given in Table 5.

\section{Mechanical thrombectomy}

Case 3: 26-year-old patient with brainstem ischemic stroke 
Citation: Knap D, Kirmes T, Honkowicz M, Koroński M, Kysiak M, et al. (2016) Treatment of Basilar Artery Occlusion using Various Techniques of Interventional Radiology. J Vasc Med Surg 4: 241. doi:10.4172/2329-6925.1000241

Page 3 of 4

\begin{tabular}{|c|c|c|c|c|c|c|c|}
\hline Age/Gender & Risk factors & $\begin{array}{c}\text { NIHSS } \\
\text { before treatment }\end{array}$ & $\begin{array}{c}\text { NIHSS } \\
\mathbf{2 4} \text { hours after } \\
\text { surgery }\end{array}$ & $\begin{array}{c}\text { NIHSS } \\
\mathbf{7} \text { days after } \\
\text { surgery }\end{array}$ & $\begin{array}{c}\text { NIHSS } \\
\mathbf{3 0} \text { day after } \\
\text { surgery }\end{array}$ & $\begin{array}{c}\text { mRS } \\
\mathbf{3} \text { months after } \\
\text { surgery }\end{array}$ & $\begin{array}{c}\text { Complications } \\
\text { of endovascular } \\
\text { treatment }\end{array}$ \\
\hline $49 / \mathrm{M}$ & $\begin{array}{c}\text { Hypertension, } \\
\text { Previous stroke }\end{array}$ & 31 & 28 & 17 & 15 & 4 \\
\hline
\end{tabular}

Table 4: Case 1

\begin{tabular}{|c|c|c|c|c|c|c|c|c|}
\hline Age/Gender & Risk factors & $\begin{array}{c}\text { NIHSS } \\
\text { before } \\
\text { treatment }\end{array}$ & \begin{tabular}{|c|} 
NIHSS \\
24 hours after \\
surgery
\end{tabular} & $\begin{array}{l}\text { NIHSS } \\
7 \text { days after } \\
\text { surgery }\end{array}$ & $\begin{array}{c}\text { NIHSS } \\
30 \text { day after } \\
\text { surgery }\end{array}$ & \begin{tabular}{|c|} 
mRS \\
3 months \\
after surgery
\end{tabular} & $\begin{array}{c}\text { Complications } \\
\text { of endovascular } \\
\text { treatment }\end{array}$ & $\mathrm{TICl}$ \\
\hline $58 / \mathrm{M}$ & $\begin{array}{l}\text { Hypertension, Diabetes } \\
\text { mellitus type } 2, \\
\text { Atherosclerosis, Ischaemic } \\
\text { heart disease, Hypertrophic } \\
\text { cardiomyopathy }\end{array}$ & 23 & 24 & 34 & 34 & 5 & - & $2 a$ \\
\hline
\end{tabular}

Table 5: Case 2

\begin{tabular}{|c|c|c|c|c|c|c|c|c|}
\hline Age/Gender & Risk factors & $\begin{array}{c}\text { NIHSS } \\
\text { before treatment }\end{array}$ & \begin{tabular}{|c|} 
NIHSS \\
24 hours after \\
surgery
\end{tabular} & $\begin{array}{l}\text { NIHSS } \\
7 \text { days after } \\
\text { surgery }\end{array}$ & $\begin{array}{c}\text { NIHSS } \\
30 \text { day after } \\
\text { surgery }\end{array}$ & $\begin{array}{c}\text { mRS } \\
3 \text { months } \\
\text { after surgery }\end{array}$ & $\begin{array}{l}\text { Complications } \\
\text { of endovascular } \\
\text { treatment }\end{array}$ & $\mathrm{TICl}$ \\
\hline $26 / M$ & $\begin{array}{l}\text { Hypertension, } \\
\text { Hiperlipidemia }\end{array}$ & 18 & 16 & 7 & 7 & 1 & - & 3 \\
\hline
\end{tabular}

Table 6: Case 3.

\begin{tabular}{|c|c|c|c|c|c|c|c|c|}
\hline Age/Gender & Risk factors & $\begin{array}{l}\text { NIHSS } \\
\text { before } \\
\text { treatment }\end{array}$ & \begin{tabular}{|c|} 
NIHSS \\
24 hours after \\
surgery
\end{tabular} & $\begin{array}{l}\text { NIHSS } \\
7 \text { days after } \\
\text { surgery }\end{array}$ & $\begin{array}{c}\text { NIHSS } \\
30 \text { day after } \\
\text { surgery }\end{array}$ & \begin{tabular}{|c|} 
mRS \\
$\begin{array}{c}\text { months after } \\
\text { surgery }\end{array}$
\end{tabular} & $\begin{array}{l}\text { Complications } \\
\text { of endovascular } \\
\text { treatment }\end{array}$ & $\mathrm{TICl}$ \\
\hline $75 / M$ & $\begin{array}{l}\text { Previous stroke, } \\
\text { Myocardial infarction, } \\
\text { Hypertension, Systemic } \\
\text { atherosclerosis }\end{array}$ & 20 & 19 & 19 & 12 & 5 & - & 3 \\
\hline
\end{tabular}

Table 7: Case 4.

recognized in head NMR test. In order to confirm the diagnose, head CT angiography and Digital Subtraction Angiography (DSA) test were performed. They showed basilar artery occlusion on the whole length with all branches. The patient was disqualified from intravenous thrombolysis due to overrunning the therapeutic time window (time of symptoms duration-over 4,5 hours). At first he was not qualified for mechanical thrombectomy also due to overrunning the time window (over 15 hours). However, in spite of contraindications the patient was undergone the procedure of mechanical thrombectomy with Solitaire FR stent. The interventions were performed by puncturing right femoral artery and inserting catheter with Seldinger method. Control DSA test showed the left vertebral artery and basilar artery with its branches. The right posterior cerebral artery was not seen, however it was seen in angiography of the right common carotid artery. Control head CT angiography showed that basilar artery is patent in its full length. Head CT and MR tests revealed ischemic changes in the left cerebellar hemisphere and the left part of brainstem. The patient's characteristics were given in Table 6.

Case 4: 75-year-old patient with suspicion of stroke. Head CT angiography showed the lack of contrast in both basilar artery and the right vertebral artery. DSA pan-angiography of cerebral vessels was performed and the patient was qualified for thrombectomy due to the narrowing of the lower part of basilar artery and the last segment of the right vertebral artery. The intervention was performed by puncturing the right axillary artery and inserting catheter to the right vertebral artery with Seldinger method. Then the Solitare FR device was inserted with microcatheter, receiving blood flow in the lower segment of basilar artery. In control angiography performed after the procedure, the right vertebral artery and basilar artery with branches were shown. Head CT showed new small ischemic strokes with no signs of hemorrhage in the area vascularized by right and left posterior inferior cerebellar artery. The patient's characteristics were given in Table 7.

\section{Bridging endovascular treatment}

Targeted Thrombolysis and Mechanical Thrombectomy-Penumbra Device.

Case 5: 37-year-old patient with suspicion of brainstem ischemia due to thrombus in the left vertebral artery and basilar artery. Head CT showed no pathological changes. However, CT angiography revealed lack of contrast in basilar artery and left vertebral artery. The patient was qualified for intra-arterial thrombolysis. A catheter was inserted with Seldinger method into the left vertebral artery by puncturing the right femoral artery. $25 \mathrm{mg}$ of Actylise was applied and partial blood flow was obtained. In control angiography, performed by inserting a catheter selectively into the left vertebral artery, embolic material was revealed. It was decided to implement the procedure of mechanical thrombectomy. Microcatheter 0,42 of Penumbra device was inserted coaxially. Blood flow was restored in the last segment of the left vertebral artery and basilar artery with branches. Control angiography confirmed the patency of both vessels. Head MR DWI showed ischemic changes in the left cerebellar hemisphere and in pons. The patient's characteristics were given in Table 8 .

\section{Results}

5 patients with basilar artery occlusion were analyzed and all of them were undergone endovascular methods of treatment.

The patients' neurological state according to NIHSS scale immediately before the treatment:

- Ranged from 18 to 31 pts (mean 22,6; SD $\pm 5,02$ ) 
Citation: Knap D, Kirmes T, Honkowicz M, Koroński M, Kysiak M, et al. (2016) Treatment of Basilar Artery Occlusion using Various Techniques of Interventional Radiology. J Vasc Med Surg 4: 241. doi:10.4172/2329-6925.1000241

Page 4 of 4

\begin{tabular}{|c|c|c|c|c|c|c|c|c|}
\hline Age/Gender & Risk factors & $\begin{array}{c}\text { NIHSS } \\
\text { before treatment }\end{array}$ & $\begin{array}{c}\text { NIHSS } \\
24 \text { hours after } \\
\text { surgery }\end{array}$ & $\begin{array}{c}\text { NIHSS } \\
7 \text { days after } \\
\text { surgery }\end{array}$ & $\begin{array}{c}\text { NIHSS } \\
30 \text { day after } \\
\text { surgery }\end{array}$ & $\begin{array}{c}\text { mRS } \\
\begin{array}{c}3 \text { months after } \\
\text { surgery }\end{array}\end{array}$ & $\begin{array}{c}\text { Complications } \\
\text { of endovascular } \\
\text { treatment }\end{array}$ & $\mathrm{TICl}$ \\
\hline $37 / M$ & - & 21 & 10 & 12 & 5 & 1 & - & 3 \\
\hline
\end{tabular}

Table 8: Case 5

The patients' state after the treatment according to NHISS:

- In $24^{\text {th }}$ hour ranged from 10 to 28 pts (mean 19,$\left.4 ; \mathrm{SD} \pm 6,98\right)$

- On $7^{\text {th }}$ day from 7 to 34 pts (mean $\left.17,8 \pm 10,18\right)$

- On $30^{\text {th }}$ day from 5 to 34 pts (mean 14,$6 ; \mathrm{SD} \pm 11,54$ )

Mean time between symptoms onset to recanalization was 670 minutes (range: 265-1170 minutes). Mean time of procedures figured 147.5 minutes (range 55-250 minutes). On the $7^{\text {th }}$ day after the procedure the reduction of neurological symptoms $\geq 10$ pts NHISS was obtained in $40 \%$ of patients and on the $30^{\text {th }}$ day after the procedure the reduction of neurological symptoms $\geq 10$ pts NHISS was obtained in $60 \%$ of patients. The successful reperfusion (TICI $\geq 2 \mathrm{~b}$ ) was observed in $80 \%$ of patients and in one patient partial reperfusion was obtained (TICI $=2 \mathrm{a}$ ). The lack of disability was stated in 2 patients, which makes $40 \%$ of the examined group $(\mathrm{mRS} \leq 2)$. No patient had any complications after the procedure.

\section{Discussion}

Ischemic stroke within basilar artery occurs rarely in comparison to other vessels, especially middle cerebral artery, however even short time of brainstem ischemia results in heavy complications, disability or even death. It shows how important it is to choose the fastest and the best available therapeutic method. Intravenous thrombolytic therapy was usually the therapy of choice [13]. Intra-arterial thrombolysis reduces death rate to approximately $60 \%[14,15]$ in comparison to standard therapy with intravenous anticoagulants approaching 90\% [5,7]. Studies carried on 344 patients indicates that intra-arterial thrombolysis efficacy of recanalization reaches $65 \% .23 \%$ of patients had good clinical outcome without disability (mRS 0-2). Symptomatic subarachnoid hemorrhage occurred in $8 \%$ of patients and $55 \%$ of patients died [16]. In BASICS research efficacy of recanalization was $69 \%, 11 \%$ of patients reached mRS $0-2$. Death rate was $49 \%$ and in $14 \%$ of patients subarachnoidal hemorrhage occurred [17]. Recanalisation failure was proven to associate with very low probability of good clinical outcome [18]. Also reoclusion which occurs in approximately $1 / 6$ of patients worsens therapeutic results [19]. Nowadays the most promising mechanical thrombectomy method which allows fast and effective recanalization is Solitaire FR (81\% TICI3 for BA) [20]. Combined therapies result in good efficacy. There are reports of using cardiological stents implanted in BA [21]. Mechanical thrombectomy methods have lower risk of hemorrhages and wider time window, especially in area of the posterior part of brain, moreover these procedures can be used when intra-arterial thrombolysis is ineffective. The crucial problem is the time from the symptoms onset to diagnosis and start of the treatment. Shortening this time and development of endovascular treatment for BAO can give patients better chance to survive and avoid severe complications and disability.

Our work shows that use of endovascular treatment methods is the alternative for standard treatment methods in patients with BAO especially those excluded from IV thrombolysis due to exceeded time window or with whom IV rt-PA administration was ineffective.

\section{Disclosure of Interest}

No potential conflict of interest relevant to this article was reported.

\section{References}

1. Baker $A B$, lannone $A$ (1959) Cerebrovascular disease. I. The large arteries of the circle of Willis. Neurology 9: 321-332.

2. Voetsch B, DeWitt LD, Pessin MS, Caplan LR (2004) Basilar artery occlusive disease in the New England Medical Center Posterior Circulation Registry. Arch Neurol 61: 496-504

3. Israeli-korn SD, Schwammenthal $\mathrm{Y}$, Yonash-Kimchi T, Bakon M, Tsabari R, et al. (2010) Ischemic stroke due to acute basilar artery occlusion: proportion and outcomes. Isr Med Assoc J 12: 671-675.

4. Archer CR, Horenstein S (1977) Basilar artery occlusion: Clinical and radiological correlation. Stroke 8: 383-390.

5. Hacke W, Zeumer H, Ferbert A, Brückmann H, del Zoppo GJ (1988) Intraarterial thrombolytic therapy improves outcome in patients with acute vertebrobasilar occlusive disease. Stroke 19: 1216-1222.

6. Cruz-Flores S (2015) Basilar Artery Thrombosis Treatment \& Management. Medscape.

7. Kubik CS, Adams RD (1946) Occlusion of the basilar artery; a clinical and pathological study. Brain 69: 73-121.

8. Labauge R, Pages M, Marty-Double C, Blard JM, Boukobza M, et al. (1981) Occlusion of the basilar artery: a review with 17 personal cases (author's transl). Rev Neurol (Paris) 137: 545-571.

9. Rha JH, Saver JL (2007) The impact of recanalization on ischemic stroke outcome: a meta-analysis. Stroke 38: 967-973.

10. Saqqur M, Uchino K, Demchuk AM, Molina CA, Garami Z, et al. (2007) Site of arterial occlusion identified by transcranial Doppler predicts the response to intravenous thrombolysis for Stroke. Stroke 38: 948-954.

11. Arnold M, Fischer U, Compter A, Gralla J, Findling O, et al. (2010) Acute basilar artery occlusion in the Basilar Artery International Cooperation Study: does gender matter? Stroke 41: 2693-2696.

12. http://www.journals.elsevier.com/neurologia-i-neurochirurgia-polska/

13. Yu W, Binder D, Foster-Barber A, Malek R, Smith WS, et al. (2003) Endovascular embolectomy of acute basilar artery occlusion. Neurology 61: 1421-1423.

14. Levy El, Firlik AD, Wisniewski S, Rubin G, Jungreis CA, et al. (1999) Factors affecting survival rates for acute vertebrobasilar artery occlusions treated with intra-arterial thrombolytic therapy: a metaanalytical approach. Neurosurgery 45: $539-545$

15. Eckert B, Kucinski T, Pfeiffer G, Groden C, Zeumer H (2002) Endovascular therapy of acute vertebrobasilar occlusion: Early treatment onset as the most important factor. Cerebrovasc Dis 14: 42-50.

16. Lindsberg PJ, Mattle HP (2006) Therapy of basilar artery occlusion: a systematic analysis comparing intra-arterial and intravenous thrombolysis. Stroke 37: 922-928.

17. Schonewille WJ, Wijman CA, Michel P, Rueckert CM, Weimar C, et al. (2009) Treatment and outcomes of acute basilar artery occlusion in the Basilar Artery International Cooperation Study (BASICS): a prospective registry study. Lance Neurol 8: 724-730.

18. Mattle HP, Arnold M, Lindsberg PJ, Schonewille WJ, Schroth G (2011) Basilar artery occlusion. Lancet Neurol 10: 1002-1014.

19. Qureshi Al, Siddiqui AM, Kim SH, Hanel RA, Xavier AR, et al. (2004) Reocclusion of recanalized arteries during intra-arterial thrombolysis for acute ischemic stroke. Am J Neuroradiol 25: 322-328.

20. Costalat V, Machi P, Lobotesis K (2011) Rescue, combined, and stand-alone thrombectomy in the management of large vessel occlusion stroke using the solitaire device: a prospective 50-patient single-center study: timing, safety and efficacy. Stroke 42: 1929-1935.

21. Juszkat R, Stanislawska K, Trojanowska I, Wegorek M, Moskal J, et al. (2012) Endovascular treatment of occlusion of basilar artery. Neuroskop 14: 63-66. 